\title{
ESTIMATIVA DO RAIO DE INFLUÊNCIA DOS POÇOS DE REBAIXAMENTO DA MINA F4 E SUA ÁREA DE INTERFERÊNCIA, COMPLEXO MINEROQUÍMICO DE ARAXÁ, VALE FERTILIZANTES.
}

\author{
Marcus Vinicios Andrade Silva ${ }^{1}$; Luiz Gustavo Moraes de Macedo $^{2}$; Michelle Cintra Abud ${ }^{3}$; Vitor \\ Magalhães $\mathrm{Maciel}^{4}$
}

\section{RESUMO}

O raio de influência de um poço é a distância para qual o efeito de seu bombeamento é nulo, ou seja, é a distância limite do cone e da área de rebaixamento desse poço e pode servir de guia para prever sua interferência em um poço adjacente. Por essa razão, a alocação de poços de bombeamento destinados à captação de água para abastecimento deve, imprescindivelmente, levar em consideração o raio de influência dos poços adjacentes. Entretanto, em empreendimentos dedicados à mineração, a interferência entre poços não deve ser encarada como um fenômeno totalmente indesejado. $\mathrm{O}$ trabalho aqui apresentado discute uma proposta de estimativa para o raio de influência dos poços tubulares profundos usados para rebaixamento de nível d'água na Mina F4 (CMA). Para tal foi utilizada a equação e Sichardt que apresentou valores para o raio de influência incluindo as áreas de sobreposição, classificadas como zonas de interferência que permitiram um melhor gerenciamento da bateria de poços de rebaixamento. A aplicação da metodologia apresentada neste artigo possui como grande diferencial, a possibilidade de aplicação em outros segmentos, a exemplo de regiões agrícolas (onde existem muitos poços para irrigação, e pouca ou nenhuma rede de monitoramento) e das áreas urbanas, onde a maior parte dos poços existentes não possuem nenhum tipo de cadastro e consequentemente não são devidamente monitorados.

\section{Abstract}

The area of influence of a well is the distance to which the effect of its pumping is null, that is, the distance limit of the cone and the relegation area that well and can serve as a guide to predict its interference in an adjacent well. Therefore, the allocation of pumping wells for the consumption of water supply must indispensably take into account the radius of influence of adjacent wells. However, in projects dedicated to mining, interference between wells should not be seen as a totally unwanted. The work presented here discusses a draft estimate for the radius of influence of wells used for drawdown water in F4 Mine (CMA). To do this we used the equation and Sichardt who presented values for the radius of influence including overlapping areas classified as interference zones that allowed better management of dewatering wells. The methodology presented in this paper has as great advantage, the possibility of application in other sectors, like agricultural areas (where there are many wells for irrigation, and little or no monitoring network) and urban areas, where most of existing wells do not have any kind of record and therefore are not properly monitored.

Palavras chaves: Raio de Influência; Poços de rebaixamento; Mineração.

\footnotetext{
${ }^{1}$ Vale Fertilizantes S.A.,Av. Arafertil,N 5000-38184-270-AraxálMG,fone:34 3669-6231,fax:34 3669-6300, marcus.andrade@ valefert.com

${ }^{2}$ Vale Fertilizantes S.A.,Av. Arafertil,No 5000-38184-270-Araxá \MG, fone: 34 3669-5411, fax: 34 3669-6300, luiz.macedo@ valefert.com

${ }^{3}$ Vale Fertilizantes S.A.,Av. Arafertil,No 5000-38184-270-AraxálMG, fone:34 3669-6231,fax: 34 3669-6300, michelle.abud@ valefert.com

${ }^{4}$ Vale Fertilizantes S.A.,Av. Arafertil,No 5000-38184-270-Araxá \MG, fone: 34 3669-6388, fax: 34 3669-6300, vitor.maciel@ valefert.com
} 


\section{1 - INTRODUÇÃO}

O raio de influência de um poço é a distância para qual o efeito de seu bombeamento é nulo, ou seja, é a distância limite do cone e da área de rebaixamento desse poço (Figura 1). Embora dependa essencialmente do balanço entre a recarga do aquífero e a descarga do poço, a extensão do raio de influência (r) pode variar sensivelmente em função de fatores geológicos (porosidade, permeabilidade, faturamento, etc.), tempo de bombeamento, da condutividade hidráulica local (k) e de parâmetros do aquífero (transmissividade, nível dinâmico, estático, altura do rebaixamento, etc.).

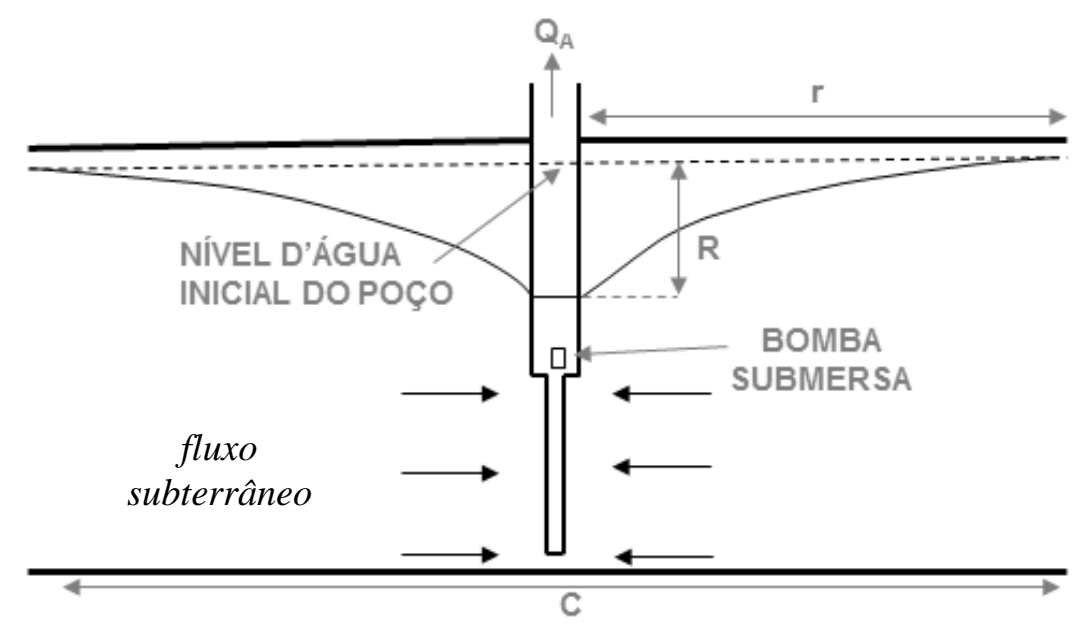

Figura 1 - Esquema do raio de influência de um poço tubular

Em aquíferos livres, sua extensão é da ordem de algumas centenas de metros, ao passo que nos aquíferos confinados sua extensão possa assumir valores da ordem de quilômetros.

O raio de influência de um poço em bombeamento pode servir de guia para prever sua interferência em um poço adjacente. Poços são ditos como em interferência quando o cone de rebaixamento de um poço se sobrepõe parcial ou totalmente ao cone de rebaixamento do outro poço adjacente (Figura 2). Isso ocorre porque o rebaixamento de um poço causa um acréscimo no rebaixamento do outro, mutuamente, podendo tornar um dos poços improdutivo (seco). 


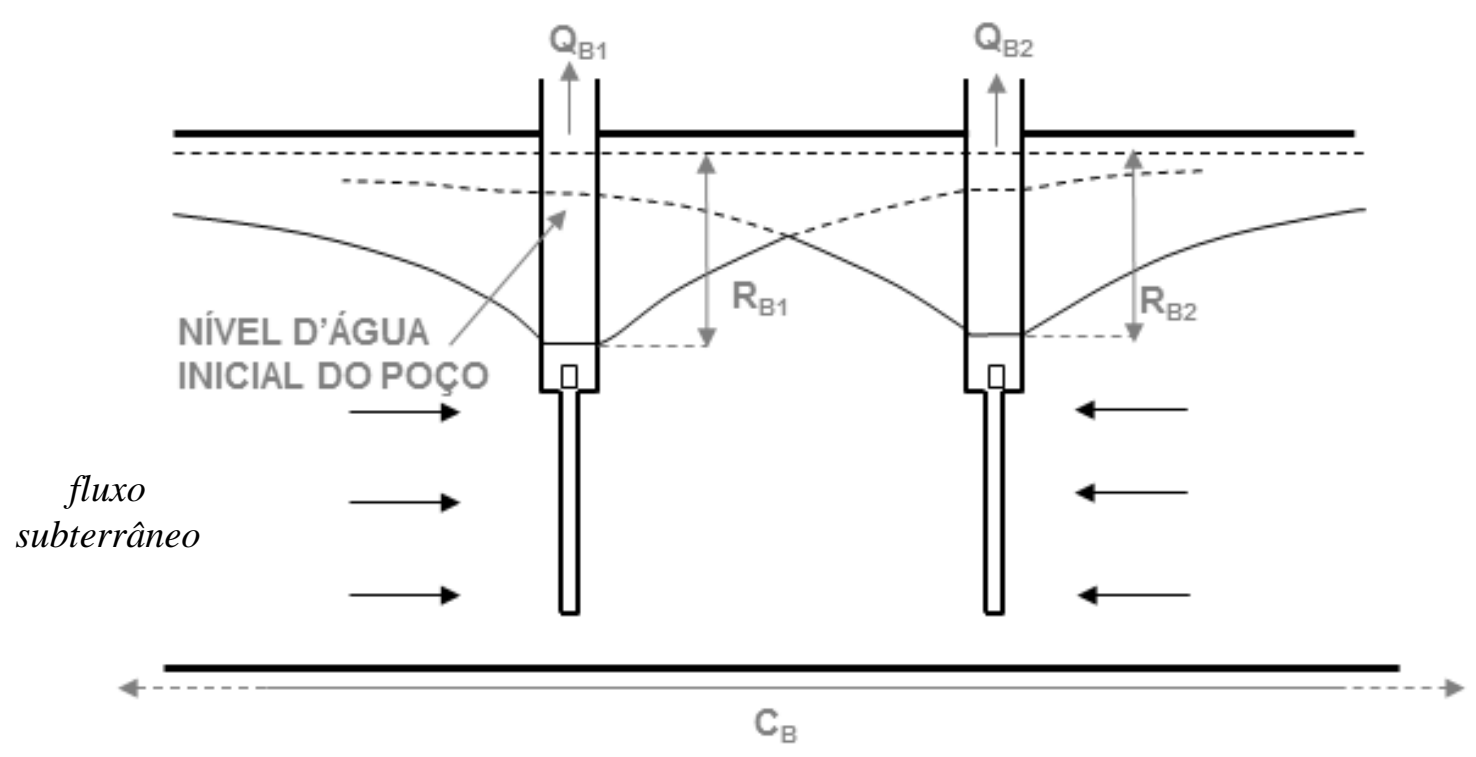

Figura 2 - Esquema de interferência entre poços

Por essa razão, a alocação de poços de bombeamento destinados à captação de água para abastecimento deve, imprescindivelmente, levar em consideração o raio de influência dos poços adjacentes, com intuito de evitar a interferência e assegurar a vazão ótima individual de cada poço.

Nesse sentido, existe grande consenso acerca da importância da determinação do raio de influência e identificação de zonas de interferência entre poços de captação e abastecimento. É possível encontrar muitos trabalhos dedicados ao assunto, sobretudo abordando regiões densamente habitadas do nordeste brasileiro, onde a água subterrânea é um recurso hídrico vital (Feitosa, 1990; Feitosa, 1997; Batista et al., 20XX; Costa et al., 2009; entre outros). Os órgãos públicos e outras entidades responsáveis pela outorga do direito de uso de recursos hídricos subterrâneos também vêm, ao longo da última década, dando atenção a esse assunto e condicionando outorgas à estimativa de influência e interferência de poços.

Entretanto, em empreendimentos dedicados à mineração, sobretudo nos quais a lavra é sustentada pelo rebaixamento do nível d'água (cavas fechadas e minas subterrâneas), a interferência entre poços não deve ser encarada como um fenômeno totalmente indesejado.

Muitas minas promovem efeito de interferência entre os poços ao instalá-los em proximidade, dentro da área do empreendimento. Isso tem sido feito nos empreendimentos da VALE FERTILIZANTES, nos municípios de Araxá (objeto do presente relato) e Tapira, ambos no Estado de Minas Gerais. Nessas localidades, poços tubulares profundos promovem rebaixamento do nível d'água em interferência mútua limitada à área do empreendimento. Graças ao contexto geológico local do depósito, conformado por um anel quartzítico, a interferência da bateria de poços do empreendimento em poços instalados na região circunvizinha é pouco provável.

É importante salientar que a rotina operacional de uma mina, avanços constantes das frentes de lavra por meio de detonações com explosivos e/ou escavações mecânicas, acaba danificando ou até mesmo destruindo instrumentos de medição de níveis (Indicadores de nível de água subterrânea 
- INAs) nas frentes de lavra, e nem sempre a reconstrução de novos INAs nas proximidades daqueles perdidos é possível, acarretando uma necessidade de usar constantemente a rede de monitoramento regional para determinar a superfície potenciométrica destas frentes de lavra, fazendo uso por exemplo de técnicas avançadas de interpolação de dados como a geoestatística.

Este artigo apresenta uma metodologia baseada na literatura existente para se determinar a os raios teóricos de influência dos poços de rebaixamento localizados em frentes de lavra, e tal método também pode ser utilizado para poços localizados em áreas onde não haja nenhum tipo de instrumento de monitoramento nas adjacências do poço.

\section{2 - Metodologia de RAIO DE INTERFERÊNCIA}

Num regime permanente, devido à estabilização do nível d'água, o raio de influência tende a assumir um valor constante. Através de métodos gráficos, o intercepto de um gráfico distância vs. rebaixamento (distance-drawdown) no eixo da distância corresponde ao raio de influência (rebaixamento igual à zero). O método gráfico está condicionado à existência de postos de observação do rebaixamento (outros poços, indicadores de nível d'água, etc.) instalados nas proximidades do poço em bombeamento.

Matematicamente, o método mais utilizado para a determinação do raio de influência $(r)$ para qualquer regime de escoamento em meio poroso é a equação empírica de Sichardt (Equação 1):

$$
r=\mathrm{C}^{*}(\mathrm{H}-\mathrm{h}) * \sqrt{k} \quad(\text { Equação 1) }
$$

A equação de Sichardt relaciona a condutividade hidráulica do aquífero com a variação do nível d'água devido ao bombeamento, parâmetros de fácil obtenção. No presente estudo, $k$ pôde ser expresso pela aproximação de Dupuit \& Forchheimer, descrito pela Equação 2:

$$
k=T / b \quad(\text { Equação 2) }
$$

A transmissividade pode ser calculada em função da vazão e a variação de nível d'água num intervalo de tempo conhecido (teste de vazão), expresso pela Equação 3:

$$
T=\frac{Q}{4 \pi\left(d_{2}-d_{1}\right) \ln \frac{t_{2}}{t_{1}}} \quad \text { (Equação 3) }
$$

Os valores obtidos por intermédio das fórmulas acima citadas (equações 2 e 3), associado aos dados provenientes dos testes de vazão possibilitou a identificação de valores de condutividade

hidráulica local para cada poço. A distinção desses valores influencia diretamente no cálculo do raio de influência (r).

O raio de influência de cada poço da Mina F4 (CMA) foi calculado, mais uma vez segundo a equação de Sichardt. Como parâmetros, foram usados os níveis d'água estático e dinâmico medidos 
durante o teste de vazão e valor da condutividade hidráulica obtida pela aproximação de Dupuit \& Forchheimer a partir de dados de teste de bombeamento. A tabela abaixo (Tabela 2) indica os parâmetros usados no calculo matemático.

Tabela 1 - Raio de influência dos poços da Mina F4 (CMA).

\begin{tabular}{|c|c|c|c|c|c|c|c|}
\hline \multicolumn{8}{|c|}{ POÇOS DE REBAIXAMIENTO DA MINA F4 (CMA) } \\
\hline & PP07 & PP08 & PP09 & PP10 & PP11 & PP12 & PP13 \\
\hline $\begin{array}{l}\text { Coeficiente de } \\
\text { transmissividade }\left(\mathrm{m}^{2} / \mathrm{s}\right)\end{array}$ & 2.91E-03 & $4.04 \mathrm{E}-03$ & $5.44 \mathrm{E}-03$ & $2.55 \mathrm{E}-05$ & $5.46 \mathrm{E}-03$ & $2.37 \mathrm{E}-03$ & 8.39E-05 \\
\hline $\begin{array}{l}\text { Condutividade } \\
\text { hidráulica }(k) \\
(\mathrm{m} / \mathrm{s})\end{array}$ & $5.60 \mathrm{E}-05$ & $3.97 \mathrm{E}-05$ & $6.91 \mathrm{E}-05$ & 2.19E-07 & 5.99E-05 & $3.31 \mathrm{E}-05$ & $9.23 \mathrm{E}-07$ \\
\hline $\begin{array}{l}\text { Raio de influência }(r) \\
(\mathrm{m})\end{array}$ & 335.06 & 369.73 & 313.87 & 144.37 & 715.83 & 526.94 & 172.61 \\
\hline
\end{tabular}

\section{3 - CONCLUSÕES}

Um dos maiores desafios enfrentados pela hidrogeologia em depósitos minerais provenientes da intemperização de intrusões alcalinas, como no Complexo Mineroquímico de Araxá, é sua grande diversidade litológica vertical e horizontal.

Essa diversidade litológica resulta em parâmetros hidrogeológicos pouco homogêneos ao longo do corpo mineralizado, dificultando a alocação de poços de rebaixamento e, consequentemente, a determinação de seu raio de influência e a interferência entre poços. Entretanto, abordagens matemáticas, por meio de modelos matemáticos e aproximações empíricas têm se mostrado bastante consistentes com a realidade observada em campo e cada vez mais úteis nas rotinas de hidrogeologia das minas da VALE FERTILIZANTES.

A determinação matemática dos raios de influência ou do cone de rebaixamento dos poços em operação na Mina F4 (PP-07, PP-08, PP-09, PP-10, PP-11, PP-12 e PP-13) permitiu delimitar a área de interferência entre eles (Anexo 1). $\mathrm{O}$ raio de influência dos poços varia em função da transmissividade e da condutividade hidráulica locais.

É importante ressaltar que a conformação dômica do depósito, delimitado por um anel quartzítico impermeável, faz com que o compartimento aquífero nele desenvolvido (no depósito) não tenha conexões com o aquífero externo ao domo. Por esse motivo, podemos assumir com segurança que a bateria de poços da Mina F4 não exerce influência nas águas subterrâneas do entorno do empreendimento, nem tampouco interfere em poços que, por ventura, estejam ou venham a ser instalados aos arredores do domo.

Finalmente, o cenário de interferência configurado entre os poços da bateria é positivo e uma das razões pela qual o rebaixamento do nível d'água na Mina F4 tem sido eficiente e possibilitado a retirada do minério. 
O trabalho aqui apresentado discute uma proposta de estimativa para o raio de influência dos poços tubulares profundos usados para rebaixamento de nível d'água na Mina F4 (CMA). Para tal foi utilizada a equação e Sichardt que apresentou valores para o raio de influência incluindo as áreas de sobreposição, classificadas como zonas de interferência. Interferência esta evidenciada na frente de lavra permitindo um melhor gerenciamento da bateria de poços de rebaixamento.

É importante salientar que esta mesma metodologia pode ser aplicada em diversos cenários, tais como áreas agrícolas e até mesmo urbanas onde não haja rede de monitoramento para determinação dos raios de influência/interferência dos poços utilizados para irrigação e/ou abastecimento. 


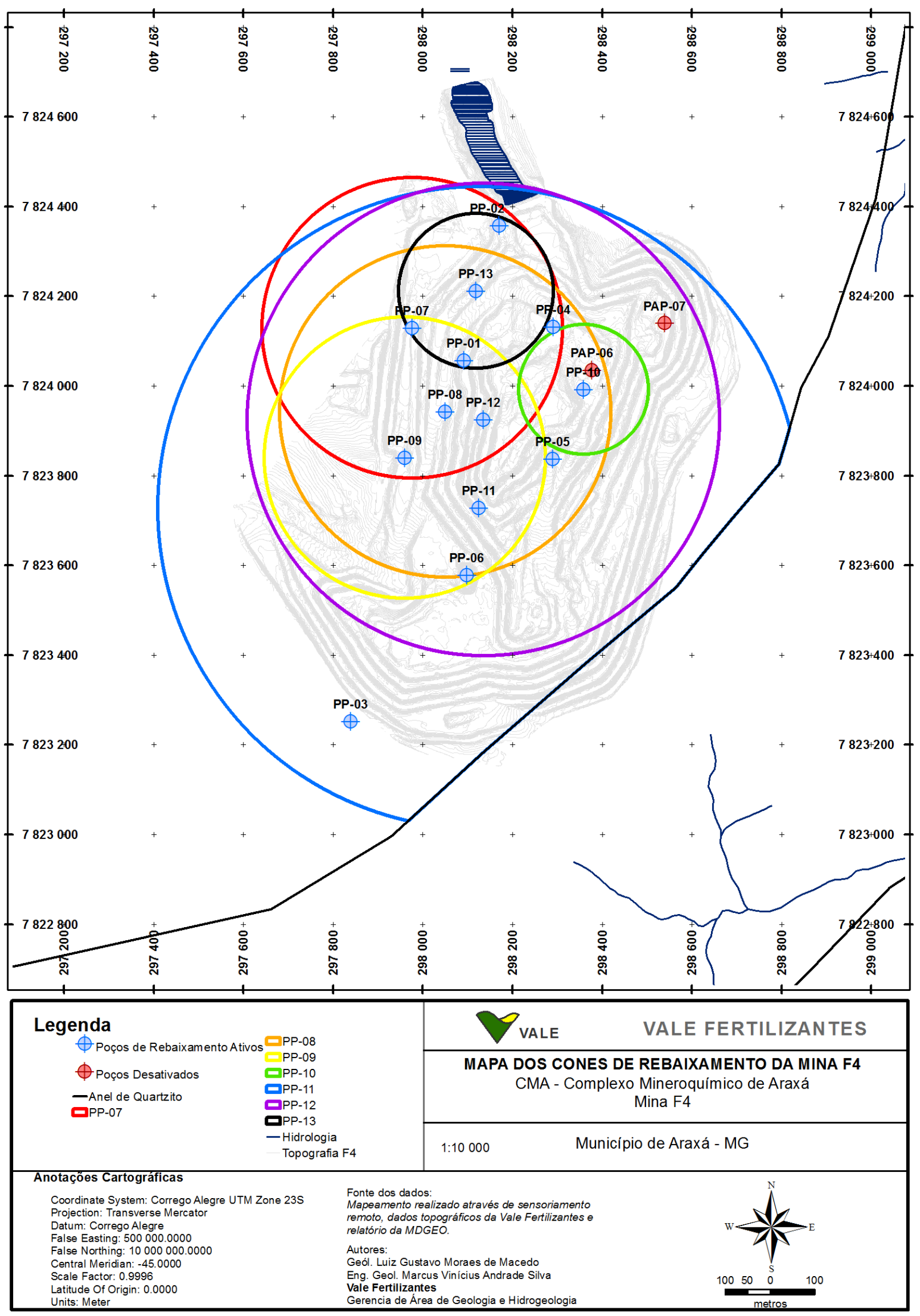

Anexo 1 - Mapa dos cones de rebaixamento da Mina F4 


\section{REFERENCIAS}

ABUD, M. C. et al. Operação e manutenção dos poços de rebaixamento em mina a céu aberto, um estudo de caso do complexo mineroquímico de Araxá da Vale Fertilizantes. In: CONGRESSO BRASILEIRO DE ÁGUAS SUBTERRÂNEAS, 18., ENCONTRO NACIONAL DE PERFURADORES DE POÇOS, 19., FENÁGUA - FEIRA NACIONAL DA ÁGUA, 8., 2014, Belo Horizonte. Anais... Belo Horizonte: Associação Brasileira de Águas Subterrâneas, 2014.

BERTACHINI, A. C.; ALMEIDA, D. C. O rebaixamento do nível d'água em mineração e obras civis. In: ENCONTRO NACIONAL DE PERFURADORES DE POÇOS, SIMPÓSIO DE HIDROGEOlOGIA DO SUDESTE, 13., 2003, Petrópolis, RJ. Anais... Petrópolis: Associação Brasileira de Águas Subterrâneas, 2003.

BIONDI, J. C. 2003. Processos Metalogenéticos e Depósitos Minerais Brasileiros. 477p., São Paulo: Oficina de Textos.

SILVA, M.V.A., Castro, S.A.B, Trindade, A.C.C., Abud, M.C., Saito, M.K., Filho, F.S. 2012. Proposta de geração de mapas potenciométricos 2D e 3D da mina F4 da Vale Fertillizantes S.A., Araxá MG. XVII Congresso Brasileiro de Águas Subterrâneas, Bonito MS. 